\title{
29
}

\section{Learning from experience: approaching the research of CD-ROM in schools}

\author{
Michael Hammond \\ Division of Education, \\ University of Sheffield \\ United Kingdom
}

\begin{abstract}
This paper draws parallels between early research into educational computing and first attempts at researching CD-ROM in schools. It argues that early research in IT was dominated by the idea that the computer would, in itself, provide general educational benefits, and that this is also a characteristic of some research into CD-ROM in schools. The discussion explores three issues: the extent to which research into CD-ROM is concentrating on the program and not the learner, the limitations of surveys into the use of CD-ROM and the value of personal testimonials. The paper outlines several questions concerning the impact of CD-ROM on learning and argues that these can best be addressed by drawing on past research and by carrying out studies which explore the interaction of learning variables. Such research may take place within a variety of frameworks.
\end{abstract}

Main conference themes: evaluation, methodologies, visions

Educational areas:

Study topics:

Secondary keywords: CD-ROM, multimedia, research 


\section{INTRODUCTION}

Maddux [1] has characterized the first stage of research into IT as dominated by the notion that exposure to the computer would in itself provide general educational benefits. Research consisted largely of "position papers" and personal testimonials, and much of the experimental work concerned scarcity of equipment.

There are obvious problems in characterizing early research into IT. For example, what is the distinction between a case study and a personal testimonial, and what was the exact nature of our strong interest in Logo? However, Maddux' description will resonate with anyone involved in the educational use of IT and is a useful reference point in considering our first attempts to understand CD-ROM in schools. In particular I suggest that three characteristics of early research into computers in schools are being reworked in some of the research into CD-ROM. These are:

- a focus on the program, not on the learner;

- surveys into computer use which are weak on pedagogic understanding;

- personal testimonials which are uncritical.

Each of these characteristics is explored in the following and the critical question is asked: Where do we go from here?

\section{Where is the Research?}

Addressing any of the above issues raises the question, Whose research are we considering? In the UK academic journals there is little research reported specifically focused on CD-ROM in schools, though see Perzylo [2]. So we need to trawl more widely. Any selection from this literature must be selective; sources quoted in this paper include a NCET report into CD-ROM [3], a statement of the value of multimedia, Ambron [4], and two accounts from a professional journal, Wilson [5] and Rouse [6]. These all illustrate some features of "stage one" research. There is of course a wider literature which does tackle issues associated with CD-ROM and multimedia much more critically, for example Jacobs [7] and Laurillard [8, pp. 120-129]. But by focusing on the limitations of first research we may be better able to map out directions which future research could take. 


\section{STAGE ONE RESEARCH INTO CD-ROM: A FOCUS ON THE PROGRAM AND NOT THE LEARNER}

\section{What is the value of accessing huge quantities of information?}

The ability to access data has lead to some visionary statements by Ambron [4, p. 22]:

“... as multimedia materials develop the distinctions between teacher and student ... will blur; everyone will have access to vast stores of information, and be able to make their own way through these databases. The old standard of the teacher as repository of knowledge will be replaced by the teacher as expert guide."

The tone is much more cautious, but nonetheless enthusiastic, in the first large scale report into CD-ROM in schools, NCET [3]. This concentrated on the use in schools of encyclopaedias and newspapers on CD-ROM - a reflection of the fact that most CD-ROMs were placed in libraries and reference materials were the most popular discs.

The evaluation of these reference materials is positive, particularly in cases where students have been given the freedom to interrogate the databases for themselves. However the concentration on the quantity of information ducks some critical issues. For example, Ambron [4, p. 29] quotes one head of resources with approval:

"CD-ROMs make students more selective. I have seen students with over 100 articles from a newspaper on their subject. Yet they go away with just two printouts. They have been able to make a very accurate assessment of what they need. They do not do this with books."

The CD-ROM is an excellent means for enabling the access of information but is information being confused with knowledge? For example, are students aware that articles in The Times or The Guardian are necessarily a selective view of events? What are students going to do with the articles? How far do critical faculties emerge from a detailed study of one text rather than a shallow overview?

\section{What is implied in the organization of materials?}

CD-ROM materials are often organized so as to allow users an easy way to follow ideas by checking on keywords, images or icons. Materials linked in this way are often described as hypermedia and aim to match the free flow of ideas in the mind rather than the linear structure of a book. Much is made of this principle which of course is not exclusive to CD-ROM. 
Hypermedia can be an effective way of organizing materials, but the links between the text and images have been constructed by the author. Some critical issues here are:

- How far do the links parallel the "free form of ideas in the mind"?

- What kind of associations does the user expect to find?

- How far does hypermedia break down an argument into small chunks and so lose the richer, extended argument of a book?

Similar issues present themselves in a consideration of authoring of hypermedia. For the moment, students' presentations in schools are usually produced on floppy or hard disc using programs such as Genesis, Magpie and Hypercard, see for example Wilson [5]. However some schools are experimenting with producing CD-ROM and this should soon become more affordable. Should we look forward to this? In a discussion of Hypercard presentations, Hofmeister $[9$, p. 220] argues:

"In the constructivist classroom, the teacher and the student are engaged together in learning... Put a computer in this kind of classroom and the teacher and the student begin to use it immediately. The computer used as a mind tool becomes another way to gather, organise, present, analyse and edit. Now all the information can be related, through hypercard, for example, and perhaps be better understood."

Students may well find it enjoyable and interesting to author their own work, but the critical question here is: why should the organisation of work on Hypercard mean it has been better understood?

\section{What does the mix of media offer?}

CD-ROM materials frequently incorporate video and sound, thus allowing students access to a world of experiences and events previously closed to them. These could include clips of past events, events which are normally too long or too rapid for them to witness, events outside of their geographical location such as a clip of a distant city or, crucially in foreign language learning, authentic language from the target community. Aside from their instructional value such clips have a strong motivational appeal. Ambron [4, p. 22] writes:

"The ready access to full motion video and sound ... will allow instructors to vastly increase the emotional and motivational appeal of their material, which in turn, should have a dramatic effect on students and their information retention." 
Access to full motion video opens up many opportunities, but it also raises several issues:

- Has the video and interactive video been so enthusiastically received in the classroom in the past?

- Where appropriate, are students aware of issues of selectivity and bias in the images they view?

- What kinds of information do students retain better through video clips and how do they need to process the information?

Are there any advantages in viewing events, for example a clip of sulphur combusting on the CD The Periodic Table, which students can experience for themselves?

\section{STAGE ONE RESEARCH INTO CD-ROM: SURVEYS INTO COMPUTER USE}

The first major survey of CD-ROM use in schools [3] set out to evaluate both the technical and pedagogic impact of CD-ROM. Much of the report covers issues such as: where CD-ROM drives were placed in schools, the sales of selected titles, technical features to look for when buying a CD-ROM, the reliability of networking, and so on. All of this is undeniably useful. There is some discussion of the curriculum issues, but this is not well developed. For example, the case study on the database Mammals [3, p. 46] explains that the package is attractive looking, easy to use and liked by pupils. Comments from schools include that being able to hear the pronunciation of mammals' names was a help and that the disc would be useful if you were doing a project on mammals. But in what kind of project would the disc be of help? For example, it is easy to see how Charles Dickens' schoolteacher Gradgrind could have used the disc to better classify a horse, but how should it be used in today's classroom?

\section{STAGE ONE RESEARCH INTO CD-ROM: PERSONAL TESTIMONIAL}

In a new field such as CD-ROM there is clearly great value in examining personal accounts, or personal testimonials, from developers and practitioners. For example, one teacher describes his experience of using the materials Frontier 2000 and outlines some of the in-service issues, gender issues and teaching issues associated with its use in class, Rouse [6]. The tone of the 
report is enthusiastic and one easily recognizes the role of the teacher in making the project a success.

Another personal account is provided by a developer of learning materials, Florin [10], but this is less rich. It contains case studies of three interactive documentaries, the first of which explores issues surrounding the case of a black American who was denied admission to the University of Mississippi in 1961. (The material was originally produced on video disc but would lend itself easily to CD-ROM as the video footage is not extensive). Florin [10, p. 37] writes:

“...the footage is compelling, you want to learn more about the subject, and because it lets you experience historical moments as if you were a witness to them, it opens the door to deeper levels of understanding. But what is most significant here is that the story gives you a reason to study the materials."

The weakness here is that no account is taken of the classroom context. We need to know the kind of understanding students will bring to the materials, for example, will the version of events offered by the film reinforce or challenge students' existing assumptions? We need to know what is implied about the interests of young people - the film is not compelling in itself, viewers will find it compelling or not, depending on a range of factors. Finally, the "reason to study the materials" extends beyond a consideration of the strength of the materials themselves and towards an understanding of the intentions of learners and teachers.

\section{WHERE DO GO FROM HERE?}

The issue which is not fully addressed in stage-one research is a detailed consideration of the interaction of learners and learning variables. This is critical as it underlies several of the questions faced by practitioners and researcher alike, questions such as:

- Is the hype associated with interactive multimedia justified?

- What are the implications for CD-ROM for self access?

- What are the implications for the curriculum?

- How do learners (students and teachers) approach CD-ROM?

In addressing these issues we can draw on past research into IT in three ways. Firstly, we can recognize that CD-ROM is new in that it allows quick and easy access to video clips, sounds, images and to vast quantities of text, but that the materials on CD-ROM are often familiar from other contexts. 
To take three examples:

- CD ROM materials which support foreign language learning often contain model dialogues for the user to listen to and practice. Such exercises have, of course, long been presented on audio tape or on video with paper based support.

- In a second example, the School Census and Mapping Package CD-ROM contains a huge quantity of census material. However the idea of interrogating large data sets, for example with a spreadsheet or database is well established in the geography classroom.

- In a third case, the mathematics materials Number Games, part of The World of Number CD-ROM, are either familiar paper based activities or video clips modelled on a well known television broadcast. Our familiarity with these materials is not a criticism, the point being made is that research into CDROM, particularly that associated with categorizing and evaluating activities, can draw on past research into IT.

One useful approach is taken by Underwood [11]. Her discussion of databases moves seamlessly from discussing long established programs such as Key and Quest to considering new CD-ROM titles. She points out that the new technology increases the quantity of information available and allows new ways of accessing it. She ends by asking if the Crucible CD-ROM is a database or not. CD-ROM then raises new issues, but we have a knowledge base to from which to work.

Secondly, a review of past research suggests that the experimental method, characterized by Maddux as a second stage of IT research, does not offer a panacea for evaluating the impact of CD-ROM on learning. Of course comparing control groups to experimental groups may throw light on the ways in which students learn, but without detailed accounts of what went on in the classroom the experimental method is limited. The context in which students and teachers operate is too complex. In any case, the problem of comparing like with like is nearly insurmountable where CD-ROM is concerned - what, for example, does a control group do when the experimental group is searching through a whole year's back issues of The Times on CD-ROM? It is noticeable that, judging by their précis, few if any out of fifty-six mini research projects supported by a recent NCET initiative carried out an experimental study, NCET [12, pp. 25-28].

Thirdly, our research into IT in general has reached a stage in which the interaction of learning variables is seen as crucial (Maddux' third stage of IT research). Research must consider what is going on for students as well as what is going on inside the program. Laurillard [8, p. 35], for example, argues for a phenomenographic approach which assumes, "that knowledge is 
relational, and therefore sets out to describe not what is known about $\mathrm{x}$, as a natural scientist would, but how the idea of $x$, can be experienced, where the relation is between viewer and object". Such an approach would move us away from some of the technical considerations associated with early research into CD-ROM and lead us to confront more problematic or "fuzzier" issues. For example, a recent NCET report [12, p. 13] considers students' understanding of texts they have accessed on a newspaper CD-ROM, asks if they are aware of bias within the report and considers what ethical issues arise when school children access articles which deal with 'pornography' or 'Satanism'.

Inevitably such a research approach will lead to a growing number of case studies in which we try to understand what is happening for students through interviews, observation and looking at the work produced. Studies will draw on practitioner accounts with the aim of dealing more systematically with the evidence and of making teachers' 'know how' more explicit. These may or may not be undertaken within an action research context, this is another issue. The important point is that we focus on learners and not the technology.

\section{CONCLUSIONS}

There is great potential for using CD-ROM in education. By offering easy access to huge stores of information CD-ROM allows innovative approaches to information gathering. And by enabling the use of video clips CD-ROM can orientate and stimulate the learner and offer experiences not easily available by other means. We should also recognize that CD-ROM materials can be presented in an intuitive and engaging manner. However in researching the potential benefits of CD-ROM we must go beyond a description of the technology and look critically at what is going on in the classroom. This task can be tackled in a variety of ways, but necessarily case studies on the use of CD-ROM in schools have to be included. These case studies need to raise critical questions such as: What is going on in the mind of the learner? What are the intentions of the teacher? What is the learner doing with the technology? What does the technology allow the learner to do? and What are the learning outcomes? Our case studies need to be informed by an understanding of the limitations of past research into educational computing but we also need to acknowledge the insight which past research offers. 


\section{REFERENCES}

1. Maddux, C. (1993) Past and Future Stages in Educational Computing Research in Approaches to Research on Teacher Education and Technology (eds. H. Waxman $\mathrm{H}$ and G. Bright). Association for the Advancement of Computing in Education, Virginia.

2. Perzylo, L. (1993) The application of multi media CD-ROMs in schools in British Journal of Educational Technology, 24, 3 , pp. 191-197

3. NCET (1992) CD-ROM in Schools Scheme, Evaluation Report, NCET, Coventry, United Kingdom.

4. Ambron, S. (1990) Multimedia in Education in The Interactive Learning Revolution (eds. Baker, J. and Tucker, R.) Kogan Paul, London.

5. Wilson, M. (1994) The Horizon Project in Micro-Scope, Multimedia Special, Newman College, Birmingham.

6. Rouse, C. (1994) Frontier 2000 in Micro-Scope, Multimedia Special, (ibid).

7. Jacobs, G. (1992) Hypermedia and discovery based learning; a historical perpective in British Journal of Educational Technology, 23, 2, pp. 113-121.

8. Laurillard, D. (1993) Rethinking University Teaching: a framework for the effective use of educational technology, Routledge, London.

9. Hofmeister..(1990) The Birth of the Hyper School in Learning with Interactive Media (eds. S. Ambron and K. Hooper) Microsoft Press, Washington.

10. Florin, F. (1990) Information Landscapes in Learning with Interactive Media (eds. Ambron, S. and Hooper, K.) Microsoft Press, Washington.

11. Underwood, J. (1994) Databases in Computer Based Learning: Potential Into Practice, (ed. Underwood, J.) David Fulton, London.

12. NCET (1994) CD-ROM in Education, The Initial Teacher Education Scheme, NCET, Coventry. 